\title{
Exportações de petróleo e a hipótese da Maldição dos Recursos Naturais no Brasil
}

\author{
Michele Polline Verissimo* (D) \\ * Universidade Federal de Uberlândia (UFU), Uberlândia (MG), Brasil. E-mail: \\ micheleverissimo@ufu.br.
}

\begin{abstract}
Resumo
Este artigo investiga os efeitos das exportaçóes de produtos primários, com foco no petróleo, sobre o desempenho do Produto Interno Bruto (PIB) brasileiro, conforme os argumentos da literatura denominada "Maldição dos Recursos Naturais". Para isso, utiliza análise de cointegração via estimação de modelos Autorregressivos de Defasagens Distribuídas (ADRL), com dados do período 2000-2017. As evidências apontam que os efeitos das exportaçóes de petróleo são positivos para a atividade econômica no longo prazo, com robustez dos resultados quando os canais de transmissão do problema são controlados, contrariando a hipótese da maldição para o Brasil. Contudo, os efeitos são negativos no curto prazo, embora se tornem insignificantes com o controle dos canais de transmissão. Assim, verifica-se a importância da retomada dos investimentos e da melhora do quadro institucional para assegurar os benefícios do petróleo para a economia.
\end{abstract}

Palavras-Chave | Exportaçóes; Petróleo; Brasil; Modelos ARDL

Códigos-JEL | O13; F14 


\title{
Oil exports and the Natural Resource Curse hypothesis in Brazil
}

\begin{abstract}
This paper investigates the primary products exports effects, especially on oil, on the Brazilian Gross Domestic Product (GDP) performance, according to the arguments for the literature called "Natural Resources Curse". For this, it uses cointegration analysis through estimation of Autoregressive Distributed Lag (ARDL) models, with data from the 2000-2017 period. The evidence indicates that the oil exports effects are positive for economic activity in the long run, with robust results by the control of the transmission channels, contrary to the Curse hypothesis for Brazil. However, the effects are negative in the short run, although they become insignificant with the control of transmission channels. Thus, this paper verifies that investments resumption and institutional framework improvement are important to ensure the oil benefits for the economy.
\end{abstract}

KeYwords | Exports; Oil; Brazil; ARDL Models

JEL Codes | O13; F14 


\section{Introdução}

Os produtos primários ampliaram a participação na pauta brasileira de exportaçóes ao longo dos anos 2000 em decorrência da conjuntura de preços e de demanda externa favoráveis, proporcionada principalmente pelas altas taxas de crescimento da China, que se tornou a principal compradora das commodities brasileiras no período. Nesse contexto, a descoberta e a exploração do petróleo nas reservas do pré-sal acenderam a possibilidade de o Brasil alavancar ainda mais significativamente suas exportaçóes de commodities ao longo do tempo, de forma que, para além das commodities agrícolas e minerais, o país possa vir também a apresentar uma especialização em commodities energéticas.

Tal possibilidade traz duas perspectivas para a economia no longo prazo. A primeira, que é otimista, vislumbra a exploração do pré-sal como uma oportunidade de autossuficiência em petróleo, com menor dependência de importaçóes do produto e obtenção de melhores saldos comerciais. Preveem-se a geraçáo de emprego e renda com a atividade e ganhos de receita a serem disseminados para outros setores, promovendo o desenvolvimento econômico por meio de gastos com educação e saúde a partir dos fundos obtidos. Ainda se prediz a alavancagem da cadeia produtiva petrolífera (para frente e para trás), que é intensiva em conhecimento e tecnologia, estimulando gastos com Pesquisa e Desenvolvimento (P\&D) e o fomento à inovação no país.

A segunda perspectiva, mais pessimista, se baseia na ideia de que a descoberta do petróleo no pré-sal pode reforçar a especialização do país em commodities, com deslocamento dos recursos produtivos para os setores primários e apreciação cambial pela entrada de divisas decorrente das exportações do produto, reduzindo a competividade dos setores industriais e acarretando um processo de desindustrialização ligado ao problema da Doença Holandesa. Acrescenta-se a isso o contexto institucional fragilizado decorrente da dos casos de corrupçáo levantados pela Operaçáo Lava Jato, que refletem o uso inadequado dos recursos advindos da atividade petrolífera e afetam o estado de confiança dos investidores na economia.

Diante dos pressupostos kaldorianos de que os produtos industriais possuem maior elasticidade-renda em relaçâo às exportaçóes, maiores economias de escala $\mathrm{e}$ spillovers tecnológicos, a especialização da economia em produtos primários pode contribuir para a obtenção de menores taxas de crescimento do PIB no longo prazo. Ademais, a posse de recursos naturais abundantes em meio ao ambiente institucional frágil facilita a utilização das receitas obtidas em atividades de cunho 
rentista e promove a corrupção e a burocracia, limitando os efeitos da riqueza em recursos naturais sobre o crescimento. Estes são alguns dos argumentos da literatura denominada Maldição dos Recursos Naturais, que, em síntese, pressupóe que países ricos em recursos naturais apresentam menores taxas de crescimento econômico no longo prazo quando comparados a países pobres em tais recursos. Ainda, argumenta-se que tais relações se tornam mais evidentes em economias cuja participação do petróleo e dos minerais é relevante na pauta exportadora.

Nesses termos, o presente artigo objetiva analisar quantitativamente a contribuição dos produtos primários, com ênfase nas exportaçóes de petróleo, sobre o desempenho do PIB brasileiro, com base na hipótese da Maldição dos Recursos Naturais. Destarte, pretende-se verificar os efeitos do petróleo sobre a atividade econômica no curto e no longo prazos, além de investigar se os resultados são robustos quando alguns dos canais de transmissão (taxa de câmbio, investimento, abertura comercial, volatilidade dos preços dos bens primários e contexto institucional) do problema são controlados. Para isso, utiliza-se a metodologia de cointegração pela estimação de modelos Autorregressivos de Defasagens Distribuídas (ARDL), com dados do período 2000-2017.

O estudo apresenta duas contribuições principais. A primeira refere-se à avaliação dos efeitos do comportamento do setor de petróleo sobre a atividade econômica, elucidando se as perspectivas devem ser otimistas ou pessimistas em relação ao desenvolvimento do setor. Desse modo, é possível colaborar com a discussão de políticas públicas para a gestáo dos recursos captados, a fim de melhorar o bem-estar social e o progresso técnico e econômico, transformando a possível "maldição" em "bênção".

A segunda contribuição é empírica, decorrente do método aplicado, visto que a maior parte dos trabalhos sobre o tema trata de amostras mais amplas de países em análise cross-country, ou com dados em painel. Tendo em vista que os países possuem fatores específicos que afetam os efeitos dos recursos naturais sobre o produto, estudos de casos individuais são relevantes para se entender os canais de transmissão da maldição.

O artigo está organizado em cinco seções, além desta introdução. A seguir expóem-se os argumentos da literatura sobre a Maldição dos Recursos Naturais e seus possíveis canais de transmissão. Posteriormente são sistematizadas algumas evidências sobre o problema em diversas economias e apresenta-se a metodologia utilizada nesse trabalho. Por fim, são discutidos os resultados e tecidas as consideraçôes finais. 


\section{A Maldição dos Recursos Naturais e seus canais de transmissão}

A literatura sobre a Maldição dos Recursos Naturais enfatiza que a posse de recursos naturais abundantes, tais como petróleo, minerais e agrícolas, pode trazer efeitos danosos ao desempenho econômico dos países. Em outras palavras, argumenta-se que países ricos em recursos naturais tendem a apresentar taxas de crescimento econômico menores quando comparados a países pobres em tais recursos.

Todavia, cabe destacar que a riqueza em recursos naturais, por si só, não é decisiva para afetar o crescimento econômico, pois o resultado final depende de alguns canais pelos quais a maldição pode (ou não) operar. Nesse sentido, a literatura comumente aponta a tendência de longo prazo desfavorável aos preços das commodities (hipótese Prebish-Singer) e a alta volatilidade dos preços desses bens, a dificuldade de desenvolvimento da atividade manufatureira, a Doença Holandesa e a fragilidade das instituiçóes como fatores que ligam a riqueza em recursos naturais ao baixo crescimento econômico. Tais canais são resumidos a seguir, com base nos surveys de Frankel (2010) e Van der Ploeg (2011), mas a discussão é comumente sistematizada como ponto de partida em qualquer trabalho sobre o tema, como os que estão expostos na revisão da literatura empírica mais adiante.

$\mathrm{Na}$ hipótese da deterioração de longo prazo dos termos de troca (argumento de Prebisch-Singer), a tendência secular de declínio dos preços das exportaçóes das commodities diante dos produtos manufaturados amplia a desigualdade de renda dos países especializados em bens primários (periferia) relativamente aos países industrializados (centro). Soma-se a isso o fato de que os bens primários apresentam baixa elasticidade-renda da demanda, de modo que o aumento da renda mundial, ao longo do tempo, orienta o consumo para uma cesta com menor presença desses produtos. Ainda, os preços dos bens primários apresentam maior volatilidade em função de choques de oferta ou variaçóes inesperadas de demanda. Desse modo, o crescimento baseado na especialização em recursos naturais é instável, visto que a entrada de receitas decorrentes do comércio desses produtos em momentos de boom possibilita o aumento de gastos públicos, mas interrompe projetos em implantação nos períodos de quedas dos preços, o que gera incerteza em todos os setores da economia e exerce impacto negativo sobre as decisóes de investimento privado. Essa vulnerabilidade das receitas em relação aos movimentos de preços das commodities dificulta também o equilíbrio do Balanço de Pagamentos pela instabilidade na geraçấo de divisas para financiamento das importaçôes. 
O baixo crescimento em economias especializadas em recursos naturais também pode ser explicado pela dificuldade das mesmas em estruturar os setores industriais. Partindo do argumento de que a indústria é caracterizada por retornos crescentes de escala, efeitos de aprendizagem e de transbordamento tecnológico para outros setores, um setor industrial bem desenvolvido permite a ampliação da produtividade que se espalha para a economia como um todo, estimulando o aumento do produto agregado. Nesses termos, o boom de commodities, ao conduzir à especialização da economia nesses bens pela maior rentabilidade relativa oferecida, inibe a diversificação em direção às atividades manufatureiras e prejudica o crescimento econômico.

Economias intensivas em recursos naturais também estão sujeitas ao problema da Doença Holandesa. Nesse caso, de acordo com Corden e Neary (1982), o boom de commodities, devido ao aumento dos preços ou à descoberta de novos recursos, altera os preços relativos dos bens comercializáveis e não comercializáveis e promove a realocação dos recursos produtivos da indústria para os setores primários e/ou de serviços, que se tornam relativamente mais rentáveis. Este processo causa apreciação da taxa de câmbio real, prejudicando a competitividade dos setores manufatureiros, que não possuem vantagens de custos no comércio internacional. Com efeito, a participação da indústria no PIB retrai (desindustrialização) e, em consequência das características superiores da atividade industrial anteriormente mencionadas, há redução do potencial de crescimento no longo prazo (BRESSER-PEREIRA, 2008).

Finalmente, há o argumento de que a riqueza em recursos naturais pode piorar a qualidade institucional nas economias, com efeitos negativos sobre o crescimento em funçấo do desenvolvimento de um comportamento rent-seeking por parte dos produtores. Nesse sentido, as receitas obtidas podem motivar a corrupção e a burocracia nos negócios e no governo, distorcendo a alocação de recursos e reduzindo a eficiência econômica. Além disso, pressupóe-se que as receitas dos recursos naturais facilitam a adoção de políticas protecionistas aos produtores domésticos, ou outros privilégios, deixando de lado o planejamento de longo prazo voltado à diversificação da estrutura produtiva e da pauta exportadora. Nesse caso, as economias tendem a apresentar um baixo grau de abertura comercial pela adoção de medidas tarifárias, dentre outras, que protegem os setores domésticos contra a concorrência externa.

Em contraponto, existe a defesa de que a posse de recursos naturais pode beneficiar o crescimento econômico, configurando "benção" ao invés de "maldição", pois a exploração desses recursos constitui fonte de riqueza e renda, que pode ser poupada ou convertida em capital para suportar aumentos futuros do produto 
(LEDERMAN; MALONEY, 2008, BADEEB; LEAN; CLARK, 2016). Muitos países ricos em recursos naturais, tais como os Estados Unidos, Canadá e Austrália, teriam usado suas receitas para investir em educação, infraestrutura e desenvolver suas indústrias, obtendo patamares elevados de crescimento.

Ainda, há o argumento de que os efeitos potenciais dos recursos naturais sobre o crescimento econômico dependem do modo pelo qual as economias são influenciadas pelas instituições (MURSHED, 2006). Em outras palavras, a relação de causalidade entre as variáveis pode ser invertida, com as instituiçóes determinando os efeitos dos recursos naturais sobre o crescimento. Assim, países com instituiçóes transparentes e de boa qualidade, que promovam a responsabilidade e competência do Estado, podem se beneficiar dos recursos naturais, enquanto apenas os países desprovidos desses atributos tendem a sofrer a maldição.

Stijns (2001) e Frankel (2010) apontam que os efeitos positivos ou negativos dos recursos naturais sobre o crescimento se relacionam ao processo de aprendizado tecnológico envolvido na exploração destes fatores. Nesses termos, se os setores intensivos em recursos naturais forem desenvolvidos por meio de formas avançadas de conhecimento, as externalidades positivas obtidas podem ser tão fortes quanto aquelas observadas na atividade manufatureira, gerando impactos benéficos ao crescimento econômico.

No caso do petróleo brasileiro, há grandes possibilidades para promoção do desenvolvimento tecnológico, com efeitos de transbordamento para vários setores da economia, de modo que a riqueza obtida com o produto possa ser revertida em crescimento econômico, conforme os argumentos apontados por Stijns (2001) e Frankel (2010). Isso ocorre porque a exploração das reservas do pré-sal (águas profundas) requer investimentos expressivos, configurando o setor como intensivo em capital e em P\&D. Além disso, a atividade conta com ampla cadeia de fornecedores, envolvendo diversos segmentos da indústria e uma complexa rede com os demais setores da economia, que necessitam realizar investimentos contínuos em inovação a afim de aperfeiçoar ou introduzir no mercado novos equipamentos capazes de viabilizar a atividade em ambientes complexos e desafiadores (MENDES; TEIXEIRA; ROCIO, 2018).

Desse modo, Furtado (2003) e Mendes, Teixeira e Rocio (2018) apontam a oportunidade de utilização da capacidade industrial instalada no país para atender à demanda de bens de capital para exploração do petróleo, como, por exemplo, submarinos e serviços offshore. Ainda, há espaço para a inovação por meio da criação de novas tecnologias que permitam a exploração offshore a custos mais baixos e de 
forma mais sustentável ambientalmente, como a operação remota e a substituição das plataformas por equipamentos submarinos de alta tecnologia. Outra possibilidade se relaciona à ampliação das atividades de refino, agregando valor ao petróleo bruto, para que o país passe a exportar também os derivados do produto.

Nesse sentido, cabe destacar que políticas industriais e de conteúdo local coerentes e políticas de fomento ao $\mathrm{P} \& D$ são relevantes para a atividade de exploração do petróleo e, mais além, para o desenvolvimento de toda a cadeia industrial e de serviços tecnológicos a ele relacionada, de forma a estimular não somente a produção, mas também o progresso técnico, podendo evitar o cenário da maldiçâo dos recursos naturais para o Brasil.

\section{Evidências empíricas}

A hipótese da Maldição dos Recursos Naturais é investigada empiricamente por diversos autores, que desenvolvem pesquisas com diferentes amostras de países e aplicam metodologias distintas, envolvendo, sobretudo, regressóes cross-country e cointegração com dados em painel. No geral, os trabalhos analisam a validade da hipótese e os vários canais de transmissão entre a abundância de recursos naturais e o crescimento econômico. Alguns estudos enfatizam que os problemas associados à maldição são institucionais, dada a incapacidade dos governos em lidar com as altas receitas derivadas da exploração dos recursos naturais. Outros destacam que a exploração de certas commodities, como minerais e petróleo, é mais propícia à geração de ineficiências, com impactos diferentes sobre o crescimento.

Considerando os trabalhos que utilizam estimaçóes de regressôes cross-country, Sachs e Warner $(1995,1997)$, por exemplo, encontram uma relação negativa entre as exportaçóes de recursos naturais (participação no PIB) e a taxa de crescimento do PIB per capita para um conjunto de 97 países no período 1970-1989, mesmo quando se controla outras variáveis relevantes para explicar o crescimento, como nível de renda per capita inicial, grau de abertura comercial, taxa de investimento, termos de troca e eficiência governamental. Sala-i-Martin e Subramanian (2003), ao testarem os canais da volatilidade dos termos de troca, Doença Holandesa e qualidade institucional com dados de 71 países nos anos 1980 e 1990, evidenciam que os recursos naturais têm efeito negativo sobre a qualidade das instituiçóes e, assim, afetam indiretamente o desempenho econômico. Papyrakis e Gerlagh (2004), em amostra que varia de 39 a 47 países, apontam associação negativa entre os recursos naturais e o crescimento, porém, tais efeitos se tornam insignificantes quando outras 
variáveis explicativas são incluídas nas estimaçóes, tais como corrupção, investimento, grau de abertura, escolaridade e termos de troca.

Os autores que enfatizam o contexto institucional argumentam que os países ricos em recursos naturais com instituiçóes fracas alocam as receitas obtidas em atividades não produtivas, ao passo que aqueles que contam com boas instituições conseguem atrair investidores, estimulando o crescimento. Nesse sentido, Mehlum, Moene e Torvik (2006), em análise para 87 países no período 1965-1990, observam que a relação inversa entre abundância de recursos naturais e crescimento econômico é obtida para países com instituiçóes inferiores. Em linha, Arezki e Van der Ploeg (2007) obtêm evidências da maldição apenas em países com instituiçôes fracas e com baixo grau de abertura comercial.

Alguns trabalhos investigam se a ocorrência da maldição pode diferir conforme o tipo de recurso natural. Nesse sentido, Lay e Mahmoud (2004), com dados do período 1980-2000, encontram efeitos negativos da participação de minerais sobre o PIB, sendo que as relaçôes obtidas para certos produtos agrícolas são positivas. Tal resultado é semelhante ao alcançado por Pessoa (2008) para um conjunto de 119 países no período 1980-2004. Mulwa e Mariara (2016), em amostra de 47 países africanos de 1990 a 2014, observam que os produtos agrícolas e minerais exercem influência negativa sobre o crescimento, enquanto os efeitos do petróleo são positivos.

Outro conjunto de trabalhos investiga a hipótese da Maldição dos Recursos Naturais a partir da utilização de técnicas de cointegração. Por meio de estimaçôes com dados em painel, Murshed (2004) evidencia que países ricos em petróleo e minerais têm piores instituiçôes, o que causa um desempenho econômico inferior quando comparado ao dos países abundantes em bens agrícolas exportáveis. Collier e Golderis (2007) assinalam que os preços das commodities têm efeitos positivos no curto prazo sobre o crescimento do PIB per capita em 130 países no período 19632003 , sendo que tais efeitos se tornam negativos no longo prazo e estão restritos às commodities não agrícolas (petróleo e minerais) e em países com instituiçóes fracas. Tiba e Frihka (2018) encontram evidências da Maldição dos Recursos Naturais em amostra de 22 países africanos no período 1990-2013, embora melhora dos indicadores de qualidade institucional, desenvolvimento humano, abertura comercial, entrada de capitais estrangeiros e investimento tornem os efeitos dos recursos naturais positivos. Em análise para a Venezuela no período 1971-2011, Satti, Farooq e Shahbaz (2013) utilizam a metodologia ARDL e encontram efeitos negativos do petróleo sobre o crescimento do país no longo prazo, ao passo que desenvolvimento financeiro, estoque de capital e abertura comercial melhoram o crescimento. 
Por outro lado, alguns autores contestam os trabalhos que obtêm evidências favoráveis à Maldiçâo dos Recursos Naturais pelo argumento de que boa parte deles utiliza medidas consideradas inadequadas para captar a abundância em fatores naturais, como a participação no PIB ou nas exportaçôes totais. Nessa direção, a medida comumente utilizada para "abundância de recursos" deve ser interpretada como uma proxy para "dependência de recursos", pois, sendo mensurada como proporção do $\mathrm{PIB}$, é uma variável endógena afetada pelas políticas econômicas e fatores institucionais subjacentes. Assim, Brunnschweiler e Bulte (2006) empregam o estoque de recursos naturais per capita, Lederman e Maloney (2008) utilizam a razão exportaçóes líquidas de bens intensivos em recursos naturais por trabalhador, enquanto Alexeev e Conrad (2009) consideram os depósitos de hidrocarbonetos per capita e a média da produção per capita de petróleo como medidas para captar a riqueza em recursos naturais. Tais trabalhos encontram efeitos positivos dos recursos naturais sobre o crescimento.

Em síntese, as evidências empíricas quanto aos efeitos dos recursos naturais sobre o desempenho das economias não são conclusivas. Porém, há o apontamento presente em certos trabalhos de que economias especializadas em petróleo são mais propensas a sofrer a dita maldição, sobretudo, quando têm baixa qualidade em suas instituiçóes. Destarte, este artigo pretende contribuir para o debate ao investigar se as exportações de petróleo no Brasil podem ser associadas à ocorrência da Maldição dos Recursos Naturais por meio de seus efeitos de curto e longo prazos sobre o PIB.

\section{Metodologia e dados}

As exportaçóes brasileiras de produtos primários tiveram resultados expressivos ao longo dos anos 2000, sinalizando um processo de reprimarizaçáo da economia. Nesse contexto, embora o petróleo ainda apresente baixa participação relativa na pauta exportadora quando comparado a itens como soja, carnes ou minério de ferro, o aumento do peso das suas exportaçóes no PIB brasileiro é notório, passando de $0,14 \%$ em 2000 para aproximadamente $1 \%$ em 2017, enquanto na pauta exportadora tal participação expandiu de 1,6\% para 8,7\% no mesmo período, conforme dados do Ministério da Indústria, Comércio Exterior e Serviços (MDIC) (BRASIL, 2018).

Assumindo que a exploração das reservas do pré-sal continue avançando nos próximos anos, é possível que o petróleo e seus derivados passem a ser responsáveis por uma parcela mais significativa das exportaçóes e do PIB, ampliando o processo de reprimarização. Destarte, justifica-se a análise proposta neste artigo, que visa 
investigar os efeitos de curto e longo prazos das exportaçóes de petróleo e derivados sobre o desempenho do PIB brasileiro, além de avaliar seus possíveis canais de transmissão, por meio de modelos Autorregressivos de Defasagens Distribuídas (ARDL).

A metodologia ARDL aplicada à cointegração, proposta por Pesaran e Shin (1999) e Pesaran, Shin e Smith (2001), possui vantagens em relação aos testes de cointegração em variáveis não estacionárias, tais como em Johansen (1991), Phillips e Hansen (1999) e Engle e Granger (1987), e aos modelos de Vetores Autorregressivos (VAR). Uma delas é que o método pode ser aplicado em variáveis com diferentes ordens de integração, $\mathrm{I}(0)$ ou $\mathrm{I}(1)$, desde que não sejam $\mathrm{I}(2)$. O método também se mostra mais eficiente para captar relaçóes de longo prazo em amostras pequenas de dados. Ainda, um nível ótimo de defasagens pode ser determinado para cada uma das variáveis do modelo por intermédio de um critério de seleção previamente escolhido (PESARAN; SHIN, 1999).

O teste desenvolvido por Pesaran, Shin e Smith (2001) consiste em verificar se existe cointegração entre um conjunto de variáveis por meio de regressóes estimadas por Mínimos Quadrados Ordinários (MQO) com defasagens da variável dependente e das variáveis explicativas. Confirmada a existência de vetores de longo prazo entre as variáveis de interesse, estimam-se os coeficientes de longo e curto prazos dos modelos, bem como a velocidade de ajustamento ao equilíbrio de longo prazo. Para isso, o modelo ARDL para duas variáveis $y$ e $x$ é estimado na forma de vetores de correção de erros (ARDL-ECM), podendo ser especificado como se segue:

$$
\Delta y_{t}=\alpha_{0}\left|\delta_{1} y_{t-1}\right| \delta_{1} x_{t-1}\left|\sum_{l=0}^{n} \phi_{1} \Delta y_{t-1}\right| \sum_{l=0}^{n} \phi_{1} \Delta x_{t-1} \mid c_{t}
$$

Em que $\Delta$ indica primeira diferença; $\alpha_{0}$ é a constante; $\delta_{\mathrm{i}}, i=1,2, \ldots$ são parâmetros de longo prazo; $\varphi_{\mathrm{i}}, i=1,2, \ldots$ são parâmetros de curto prazo; e $\varepsilon_{\mathrm{t}}$ é o termo de erro.

Para proceder à análise, após as estimaçôes por MQO, utiliza-se o teste Wald (estatística-F) para verificação da significância conjunta dos parâmetros de longo prazo. Entretanto, sob a hipótese nula de não existência de cointegração, os valores críticos do teste Wald não possuem uma distribuição assintótica padrão para qualquer ordem de integração dos regressores. Por isso, Pesaran, Shin e Smith (2001) fornecem uma banda de valores críticos, em que o nível inferior é calculado com a hipótese de que todas as variáveis do modelo ARDL são estacionárias $\mathrm{I}(0)$ e a banda superior é calculada com a hipótese de que todas as variáveis são I(1). 
Definida a banda de valores críticos, a estatística-F do teste Wald é comparada com ela. A hipótese nula é de não existência de vetores de cointegração. Assim, se a estatística-F do teste Wald ficar abaixo da banda inferior de valores críticos, a hipótese nula não é rejeitada, ou seja, não há cointegração. Se a estatística-F for maior do que a banda superior de valores críticos, a hipótese nula é rejeitada (há cointegração). Por fim, se a estatística-F ficar dentro do intervalo de valores críticos, os resultados são inconclusivos.

Previamente à estimação dos modelos ARDL, é importante assegurar que as variáveis utilizadas não sejam integradas de segunda ordem (I(2)). Isso é feito por meio da aplicação dos testes tradicionais de raiz unitária. Além disso, testes de diagnóstico devem ser realizados, tais como o teste LM de autocorrelação dos resíduos (cuja hipótese nula é de ausência de autocorrelação) e o teste de estabilidade dos coeficientes dos modelos, via Soma Cumulativa dos Resíduos (CUSUM) e Soma Cumulativa dos Resíduos ao Quadrado (CUSUMSQ) (BROWN; DURBIN; EVANS, 1975). A instabilidade dos parâmetros é constatada se as somas cumulativas dos resíduos ultrapassarem a área entre as bandas críticas de 5\%, indicando a influência de quebras estruturais nas estimaçóes.

A investigação proposta neste artigo se baseia na estimação de duas especificaçóes de modelos ARDL aplicados à cointegração, envolvendo dados do primeiro trimestre de 2000 ao quarto trimestre de 2017 para as variáveis apresentadas a seguir,

- PIB: Produto Interno Bruto, em volume, com ajuste sazonal, referência 2010 (índice média $2010=100$ ). Fonte: Instituto Brasileiro de Geografia e Estatística (IBGE) - Contas Nacionais Trimestrais.

- XPETPIB: Participação das exportaçóes de petróleo e derivados no PIB brasileiro (em \%). Fonte: Ministério da Indústria, Comércio Exterior e Serviços (MDIC) e Instituto Brasileiro de Geografia e Estatística (IBGE) - Contas Nacionais Trimestrais.

- VOLTT: Volatilidade dos termos de troca (índice média $2010=100$ ), calculada pelo desvio-padrão da diferença entre a variável e sua tendência obtida pela aplicação do filtro Hodrick-Prescott multiplicada por 100. Fonte: Global Economics Monitor.

- DESCAMBIO: Desalinhamento da taxa de câmbio real efetiva - exportaçôes de manufaturados (índice média $2010=100$ ), obtida a partir do Filtro Hodrick-Prescott (componente cíclico). Fonte: Instituto de Pesquisa Econômica Aplicada (Ipea). 
- INV: Proxy para a acumulaçáo de capital físico (investimento) - Formação Bruta de Capital Fixo (FBKF) - em volume, com ajuste sazonal, referência 2010 (índice média $2010=100$ ). Fonte: Instituto Brasileiro de Geografia e Estatística (IBGE) - Contas Nacionais Trimestrais.

- ABERT: Grau de abertura comercial, obtido pela participação percentual da soma das exportações (US\$ milhôes) e importações (US\$ milhóes) no PIB brasileiro (US\$ milhóes). Fonte: Banco Central do Brasil (BCB).

- INST: Proxy para qualidade das instituiçóes brasileiras dada pelo Indicador de Confiança do Empresário Industrial - ICEI (condiçóes atuais Brasil). O índice varia de 0 a 100, sendo que quanto maior o índice, maior o grau de confiança. Fonte: Confederação Nacional da Indústria (CNI).

Na primeira especificação do modelo (equação 2), o objetivo é obter evidências sobre a hipótese da Maldição dos Recursos Naturais, considerando-se os efeitos das exportaçóes de petróleo e derivados (XPETPIB) sobre o desempenho do PIB brasileiro. Caso o coeficiente obtido para a variável seja negativo, a evidência é favorável à ocorrência da maldição.

$$
\triangle P I B_{t}=\alpha_{0}+\delta_{1} P I B_{t-1}+\delta_{2} X P E T P I B_{t-1}+\sum_{i=0}^{n} \phi_{1} \Delta P I B_{t-1}+\sum_{i=0}^{p} \phi_{2} \Delta X P E T P I B_{t-1}+\varepsilon_{t}
$$

$\mathrm{Na}$ segunda especificação do modelo (equação 3), investiga-se a hipótese da Maldição dos Recursos Naturais, levando em conta alguns dos possíveis canais de transmissão do problema. Nesse caso, a robustez do sinal da variável XPETPIB é avaliada controlando os efeitos da volatilidade dos termos de troca (VOLTT), do desalinhamento da taxa de câmbio real (DESCAMBIO), da acumulação de capital físico (INV) e do grau de abertura comercial (ABERT). A escolha dessas variáveis é baseada na literatura, que, em síntese, argumenta que os países ricos em recursos naturais são mais propensos a sofrer choques imprevisíveis nos termos de troca, além de contarem com taxas de câmbio sobrevalorizadas (Doença Holandesa) e baixas taxas de investimento que comprometem o desenvolvimento dos setores industriais. Ainda, tais países tendem a adotar estratégias de desenvolvimento substitutivas de importaçóes (protecionistas), lidando com baixo grau de abertura comercial.

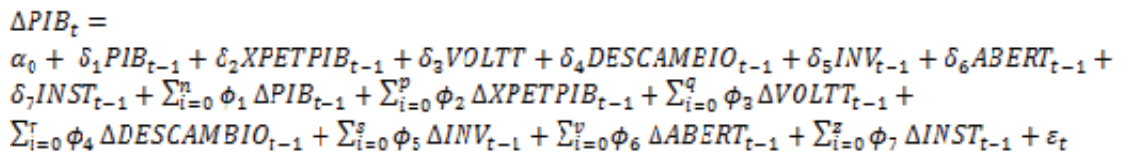


Adiciona-se também uma proxy para captar o cenário institucional brasileiro (variável INST), que reflete o grau de confiança dos empresários nas condiçôes econômicas do país, afetando suas decisóes de investimento e, portanto, o PIB. Pressupóe-se que as receitas obtidas pelos recursos naturais não beneficiam o crescimento econômico quando há problemas institucionais, tais como corrupção, burocracia e/ou políticas protecionistas aos setores primários, que prejudicam o estado de confiança dos agentes econômicos. Nesse caso, a variável INST reflete o cenário de incerteza e de desconfiança, evidenciado pela deflagração da Operaçấo Lava Jato.

O uso da variável XPETPIB, tal como nos trabalhos de Sachs e Warner (1995, 1997), busca refletir a importância do petróleo na economia. ${ }^{1}$ No entanto, tendo em vista que a participação das exportaçóes de petróleo no PIB é baixa em relação aos demais produtos primários, os modelos também são estimados considerando a participação percentual das exportaçôes de commodities totais (XCOMPIB) no PIB brasileiro (Fonte: Ministério da Indústria, Comércio Exterior e Serviços - MDIC) para avaliar a robustez dos resultados. ${ }^{2}$

Cabe destacar que, conforme os argumentos de Stijns (2001) e Frankel (2010), o desenvolvimento tecnológico (inovaçóes) e as externalidades positivas geradas nas atividades primárias também podem ser canais relevantes para se evitar a ocorrência da Maldição dos Recursos Naturais. Contudo, este trabalho não incorpora nenhuma variável capaz de representar esse efeito, visto que normalmente os dados sobre inovaçôes são disponibilizados em frequência anual, o que inviabiliza a metodologia proposta. Ademais, na literatura empírica sobre o tema, uma variável proxy para inovação não é recorrente.

Todas as variáveis foram empregadas em logaritmo natural. Também foi incluída uma variável dummy nas estimações (DCRISE), assumindo o valor 1 do terceiro trimestre de 2008 ao terceiro trimestre de 2009, para captar os efeitos da crise norte-americana (subprime). A inclusão dessa variável foi necessária para corrigir a instabilidade dos modelos (conforme os testes CUSUM e CUSUMSQ). ${ }^{3}$

1 Embora haja críticas quanto ao uso da participação das exportaçóes de recursos naturais no PIB como medida da abundância daqueles recursos, como em Brunnschweiler e Bulte (2006) e Lederman e Maloney (2008), essa especificaçấo foi mantida neste artigo devido à dificuldade em obter outros dados capazes de captar o estoque de capital natural da economia, como produçáo ou reservas, em frequência trimestral.

2 Corresponde à soma das exportaçôes de alimentos, matérias-primas năo agrícolas, minerais e combustíveis, obtidos a partir da Classificação Uniforme para o Comércio Internacional (CUCI).

3 Por questáo de espaço, os resultados dos testes CUSUM e CUSUMSQ nấo estão reportados. Contudo, podem ser solicitados à autoria do artigo. 


\section{Resultados}

Previamente às estimaçôes dos modelos ARDL, a ordem de integração das variáveis utilizadas é avaliada, visto que o método é adequado à estimação com variáveis de diferentes ordens de integração. A Tabela 1 sintetiza os resultados dos testes tradicionais de raiz unitária Augmented Dickey-Fuller (ADF), Philips-Perron (PP) e Kwiatkowski-Phillips-Schmidt-Shin (KPSS), os quais indicam que algumas variáveis são $\mathrm{I}(0)$, enquanto outras são $\mathrm{I}(1)$, sendo que nenhuma delas é $\mathrm{I}(2)$, admitindo a utilização da metodologia proposta.

TABELA 1

Testes de raiz unitária

\begin{tabular}{lccccccc}
\hline \multirow{2}{*}{ Variáveis } & \multicolumn{7}{c}{ Testes } \\
\cline { 2 - 8 } & ADF (1) & $\mathbf{k}$ & PP (2) & $\mathbf{k}$ & KPSS (3) & $\mathbf{k}$ & OI \\
\hline PIB & $-1,57$ & 1 & $-1,70$ & 3 & $1,04^{*}$ & 6 & $\mathrm{I}(1)$ \\
Exportações de Petróleo/PIB & $-3,52^{* *}$ & 0 & $-3,34^{* *}$ & 10 & $0,67^{* *}$ & 6 & $\mathrm{I}(0)$ \\
Exportações de Commodities/PIB & $-3,06^{* *}$ & 4 & $-4,68^{*}$ & 18 & $0,37^{*}$ & 5 & $\mathrm{I}(1)$ \\
Desalinhamento Taxa de Câmbio & $-4,91$ & 1 & $-2,76^{* *}$ & 9 & 0,07 & 6 & $\mathrm{I}(0)$ \\
Volatilidade Termos de Troca & $-8,56^{*}$ & 0 & $-8,56^{*}$ & 3 & 0.07 & 4 & $\mathrm{I}(0)$ \\
Investimento & $-1,31$ & 2 & $-1,38$ & 0 & $0,86^{*}$ & 6 & $\mathrm{I}(1)$ \\
Grau de Abertura Comercial & $-2,05$ & 4 & $-4,76^{*}$ & 6 & 0,34 & 5 & $\mathrm{I}(1)$ \\
Instituiçóes & $-3,42^{* *}$ & 1 & $-2,83^{* *}$ & 4 & $0,48^{* *}$ & 5 & $\mathrm{I}(0)$ \\
\hline
\end{tabular}

Fonte: Elaboração própria a partir dos resultados do Eviews 10.

(1) Augmented Dickey-Fuller.

(2) Philips-Perron.

(3) Kwiatkowski-Phillips-Schmidt-Shin.

Estimaçóes com constante.

$\mathrm{k}$ : número de defasagens.

Valores críticos testes ADF e PP: $1 \%(-3,54)$ e 5\% $(-2,90)$.

Valores críticos teste KPSS: $1 \%(0,74)$ e $5 \%(0,46)$.

$\left(^{*}\right)$ e $\left(^{* *}\right)$ rejeição de $\mathrm{H}_{0}$ a $1 \%$ e $5 \%$ de significância.

ADF e PP: $\mathrm{H}_{0}$ : Tem raiz unitária.

KPSS: $\mathrm{H}_{0}$ : Não tem raiz unitária.

A Tabela 2 exibe os resultados dos testes LM de autocorrelação dos resíduos e as defasagens selecionadas para cada variável dos modelos nas diversas especificaçóes, conforme o critério de informação de Akaike (AIC).

Destaca-se a ausência de autocorrelação serial (não rejeição da hipótese nula) em todos os modelos estimados. 
TABELA 2

Estimativas dos modelos ARDL (variável dependente: PIB)

\begin{tabular}{|c|c|c|c|}
\hline Modelos & Defasagens selecionadas & $\begin{array}{c}\text { Variáveis significativas } \\
\text { (defasagens entre parênteses) }\end{array}$ & $\begin{array}{c}\text { Teste LM } \\
\text { autocorrelaçáo } \\
{[\text { Prob] }}\end{array}$ \\
\hline 1 & $(3,4,3)$ & $\begin{array}{l}\text { PIB }(-1,-2) \text {; XPETPIB }(-1,-4) ; \text { DCRISE } \\
(-1,-3)\end{array}$ & $\begin{array}{c}0,529 \\
{[0,5922]}\end{array}$ \\
\hline 2 & $(2,0,3)$ & $\begin{array}{l}\operatorname{PIB}(-1,-2) ; \text { XCOMPIB }(0,-1) \text {; } \\
\text { DCRISE }(-1,-2)\end{array}$ & $\begin{array}{c}0,863 \\
{[0,4269]}\end{array}$ \\
\hline 3 & $(2,1,4,3,1,3,0,3)$ & $\begin{array}{l}\operatorname{PIB}(-1) ; \operatorname{XPETPIB}(-1) ; \operatorname{VOLTT}(0,-2) \text {; } \\
\operatorname{INV}(-1) ; \operatorname{ABERT}(-1) ; \operatorname{INST}(-1)\end{array}$ & $\begin{array}{c}0,343 \\
{[0,7114]}\end{array}$ \\
\hline 4 & $(2,0,4,3,1,3,0,3)$ & $\begin{array}{l}\operatorname{PIB}(-1,-2) ; \text { XCOMPIB }(0) ; \\
\text { DESCAMBIO }(-2 ;-3) \text {; VOLTT }(0) \text {; } \\
\text { INV }(0,-2,-3) \text {, INVEST }(0,-1) ; \\
\text { ABERT }(-3) ; \text { INST }(0)\end{array}$ & $\begin{array}{c}0,227 \\
{[0,7976]}\end{array}$ \\
\hline
\end{tabular}

Fonte: Elaboração própria a partir dos resultados do Eviews 10.

Após assegurar que as estimativas não possuem problemas de correlação serial, a relação de longo prazo (cointegração) entre as variáveis é examinada a partir da aplicação dos testes de limites (ARDL bounds tests), que consistem no teste Wald (F-test) para verificar a significância conjunta dos parâmetros de longo prazo dos modelos.

A Tabela 3 sistematiza os resultados obtidos, levando em conta os valores críticos de Pesaran, Shin e Smith (2001). Os testes indicam que as estatísticas-F são maiores do que os valores críticos (a 5\%), sinalizando a rejeição da hipótese de não cointegração nos modelos estimados. Em outras palavras, confirma-se a existência de relações de longo prazo entre as variáveis analisadas.

TABELA 3

Teste de cointegração ARDL (bounds limits)

\begin{tabular}{ccccccc}
\hline \multirow{2}{*}{ Modelos } & Estatística F & \multicolumn{4}{c}{ Valores críticos } & \\
\cline { 3 - 5 } & & \multicolumn{2}{c}{$\mathrm{I}(0)$ Bound } & \multicolumn{2}{c}{$\mathrm{I}(1)$ Bound } & $\begin{array}{c}\text { Cointegraçáo de } \\
\text { longo prazo? }\end{array}$ \\
\cline { 3 - 5 } 1 & $7, \%$ & $5 \%$ & $10 \%$ & $5 \%$ & Sim \\
2 & 3,69 & 2,63 & 3,10 & 3,35 & 3,87 & Sim \\
3 & 10,46 & 1,70 & 1,97 & 2,83 & 3,18 & Sim \\
4 & 9,79 & 1,70 & 1,97 & 2,83 & 3,18 & Sim \\
\hline
\end{tabular}

Fonte: Elaboração própria a partir dos resultados do Eviews 10.

$\mathrm{H}_{0}$ (não há relação de longo prazo). 
O papel de cada variável explicativa no contexto de longo prazo é reportado pela Tabela 4, que apresenta os resultados dos coeficientes de cointegração de longo prazo nos modelos estimados.

TABELA 4

Coeficientes de longo prazo (variável dependente: PIB)

\begin{tabular}{|c|c|c|c|c|}
\hline \multirow{2}{*}{ Variáveis } & \multicolumn{4}{|c|}{ Coeficientes (Prob.) } \\
\hline & Modelo 1 & Modelo 2 & Modelo 3 & Modelo 4 \\
\hline XPETPIB & $\begin{array}{c}0,183 \\
(0,0000)\end{array}$ & & $\begin{array}{c}0,061 \\
(0,0353)\end{array}$ & \\
\hline XCOMPIB & & $\begin{array}{c}2,962 \\
(0,0000)\end{array}$ & & $\begin{array}{c}0,256 \\
(0,0554)\end{array}$ \\
\hline DESCAMBIO & & & $\begin{array}{c}0,051 \\
(0,8533)\end{array}$ & $\begin{array}{c}-0,123 \\
(0,6364)\end{array}$ \\
\hline VOLTT & & & $\begin{array}{c}0,005 \\
(0,0012)\end{array}$ & $\begin{array}{c}0,004 \\
(0,0029)\end{array}$ \\
\hline INV & & & $\begin{array}{c}0,594 \\
(0,0000)\end{array}$ & $\begin{array}{c}0,626 \\
(0,0000)\end{array}$ \\
\hline ABERT & & & $\begin{array}{c}0,383 \\
(0,0061)\end{array}$ & $\begin{array}{c}0,201 \\
(0,1934)\end{array}$ \\
\hline INST & & & $\begin{array}{c}0,263 \\
(0,0574)\end{array}$ & $\begin{array}{c}0,227 \\
(0,0595)\end{array}$ \\
\hline DCRISE & $\begin{array}{c}0,167 \\
(0,1476)\end{array}$ & $\begin{array}{c}2,323 \\
(0,1613)\end{array}$ & $\begin{array}{c}-0,080 \\
(0,2641)\end{array}$ & $\begin{array}{c}-0,072 \\
(0,2681)\end{array}$ \\
\hline
\end{tabular}

Fonte: Elaboraçấo própria a partir dos resultados do Eviews 10.

No modelo 1, o coeficiente da participação das exportaçóes de petróleo no PIB (XPETPIB) possui sinal positivo e é estatisticamente significante (a 1\%), contrariando a hipótese da Maldição dos Recursos Naturais no Brasil, visto que o aumento de $10 \%$ das exportações de petróleo contribui para alavancar o PIB brasileiro em cerca de $2 \%$. A estimativa para o modelo 2 corrobora o resultado, indicando que o crescimento de $10 \%$ das exportaçóes das commodities totais (XCOMPIB) eleva o PIB em 29,6\%. Nota-se a maior elasticidade do PIB em relação aos choques das exportações do conjunto de bens primários, pois a participação das mesmas no produto agregado é mais representativa.

Nos modelos 3 e 4, os coeficientes das exportaçóes de petróleo (XPETPIB) e do total de commodities (XCOMPIB) mantêm os sinais positivos e a significância estatística (a 5\%) quando os modelos são controlados pela adição de variáveis que 
refletem os canais de transmissão da maldição. Contudo, há perda de magnitude em relação aos valores obtidos nos modelos 1 e 2, o que é explicado pela consideração dos efeitos de outras variáveis que também afetam o PIB brasileiro. Nesse caso, a ampliação de $10 \%$ das exportaçóes de petróleo contribui para estimular o PIB em pouco mais de $0,6 \%$, enquanto as exportaçóes das commodities totais impactam em 2,56\%. Verifica-se a relevância do aumento do capital físico (INV), do grau de abertura comercial (ABERT), da qualidade das instituiçóes (INST) e da volatilidade dos termos de troca (VOLTT) para explicar o desempenho do PIB brasileiro, cujos sinais são positivos e estatisticamente significantes.

O investimento é a variável com maior magnitude, indicando que um incremento de $10 \%$ no capital físico impacta o PIB em cerca de 6\% (média dos dois modelos). No caso do aumento do grau de abertura comercial, o efeito é de cerca de $4 \%$, enquanto para o indicador de qualidade institucional, o efeito é de $2,5 \%$. Tais evidências sinalizam que a maldição dos recursos naturais pode ser evitada, ou que os recursos naturais podem ser benéficos para a economia, quando controlados os canais de transmissão do problema, com as receitas obtidas pelos recursos naturais direcionadas para estimular um elevado nível de investimento, a competição externa pela abertura comercial e boas instituiçóes.

A volatilidade dos termos de troca apresenta sinal positivo, contrário ao esperado pela literatura. Isso pode ser justificado pelo fato de que, no período analisado, com exceção dos anos de 2009 e 2015, a trajetória de preços dos bens primários é de crescimento, o que indica uma melhora dos termos de troca para o Brasil. Contudo, os coeficientes obtidos são poucos expressivos, pois um aumento da volatilidade em $10 \%$ possui um efeito de $0,05 \%$ sobre o PIB. Cabe destacar que a dummy crise não foi estatisticamente significante em nenhum modelo, o mesmo sendo verificado para a variável desalinhamento cambial (DESCAMBIO).

$\mathrm{Na}$ sequência, são estimados os ajustamentos de curto prazo dos modelos ARDL, via mecanismo de correção de erros (ECM). Isso se faz necessário tendo em vista que os desequilíbrios de curto prazo sáo considerados um processo de ajustamento ao equilíbrio de longo prazo, cuja velocidade pode ser mais rápida ou mais lenta. A maior (menor) velocidade de ajustamento significa que as relaçôes de equilíbrio entre as variáveis retornam ao estado estável mais rápido (lento). A Tabela 5 informa os resultados ECM para os modelos ARDL estimados, bem como as variáveis que são estatisticamente significantes para a dinâmica de curto prazo. 
TABELA 5

Dinâmica de curto prazo: correção de erros e variáveis significativas

\begin{tabular}{|c|c|c|}
\hline Modelos & $\begin{array}{r}\text { ECM(-1) } \\
\text { [Prob.] }\end{array}$ & Variáveis significativas \\
\hline 1 & $\begin{array}{c}-0,049 \\
{[0,0000]}\end{array}$ & $\begin{array}{c}\operatorname{PIB}(-1) \\
\text { XPETPIB }(0,-1,-2,-3) \\
\operatorname{DCRISE~}(-1,-2)\end{array}$ \\
\hline 2 & $\begin{array}{c}-0,004 \\
{[0,0000]}\end{array}$ & $\begin{array}{c}\operatorname{PIB}(-1) \\
\text { DCRISE }(-1)\end{array}$ \\
\hline 3 & $\begin{array}{c}-0,058 \\
{[0,0000]}\end{array}$ & $\begin{array}{c}\operatorname{PIB}(-1) \\
\text { XPETPIB }(0) \\
\text { DESCAMBIO }(-1,-3) \\
\operatorname{VOLTT}(0,-1,-2) \\
\operatorname{INV}(0) \\
\text { ABERT }(-1,-2) \\
\text { DCRISE }(-1,-2,-3)\end{array}$ \\
\hline 4 & $\begin{array}{c}-0,064 \\
{[0,0029]}\end{array}$ & $\begin{array}{c}\operatorname{PIB}(-1) \\
\text { DESCAMBIO }(-1) \\
\operatorname{VOLTT}(-1,-2) \\
\operatorname{INV}(0) \\
\text { ABERT }(-1,-2) \\
\text { DCRISE }(0,-1,-2)\end{array}$ \\
\hline
\end{tabular}

Fonte: Elaboração própria a partir das saídas do Eviews 10.

Verifica-se que os sinais do termo de correção de erro $\left(\mathrm{ECM}_{\mathrm{t}-1}\right)$ são negativos e significantes em todas as estimativas. Contudo, os valores obtidos são baixos, indicando que o processo de ajustamento ao equilíbrio de longo prazo é bem lento, já que, no máximo, $6 \%$ dos choques das variáveis no curto prazo são corrigidos em um trimestre. Isso significa que os efeitos dos choques de curto prazo levam mais de quatro anos para serem dissipados, o que faz sentido considerando a natureza estrutural de algumas das variáveis de controle, como as instituiçóes e o estoque de capital físico, que muda lentamente.

A Tabela 5 também registra que a variável que representa as exportaçóes de petróleo (XPETPIB), dentre outras, é relevante para explicar a dinâmica de curto prazo do PIB brasileiro. Contudo, não há significância estatística no caso das exportaçóes de commodities totais. Ou seja, as exportaçóes de produtos primários impactam a atividade econômica brasileira apenas no contexto de longo prazo. Cabe destacar que os choques determinados pelo desalinhamento cambial e pela 
dummy crise se tornam estatisticamente significantes para explicar o desempenho do PIB no curto prazo.

Em complemento, a Tabela 6 exibe os coeficientes de curto prazo obtidos para a variável XPETPIB nas suas diversas defasagens. ${ }^{4}$ Nota-se que os efeitos dessas variáveis sobre o desempenho do PIB brasileiro (modelo 1) são negativos, mas de baixa magnitude, sugerindo que as exportações de petróleo não contribuem para alavancar a atividade econômica brasileira no curto prazo.

TABELA 6

Coeficientes de curto prazo para a variável de recursos naturais (petróleo)

\begin{tabular}{c|c|c}
\hline Modelos & Variáveis & Coeficientes (Prob.) \\
\hline \multirow{3}{*}{1} & D(XPETPIB) & $-0,0058(0,0646)$ \\
& D(XPETPIB $(-1))$ & $-0,0103(0,0102)$ \\
3 & D(XPETPIB $(-2))$ & $-0,0076(0,0270)$ \\
D(XPETPIB $(-3))$ & $-0,0069(0,0280)$ \\
& D(XPETPIB) & $-0,0003(0,8456)$ \\
\hline
\end{tabular}

Fonte: Elaboração própria a partir das saídas do Eviews 10.

Quando os canais de transmissão são controlados (modelo 3), a variável XPETPIB, embora negativa, perde significância estatística. Em outras palavras, as evidências são frágeis para se qualificar a hipótese da Maldição dos Recursos Naturais no Brasil.

\section{Considerações finais}

Este artigo analisa empiricamente os efeitos da participação dos recursos naturais, com ênfase no petróleo, sobre o PIB brasileiro nos anos 2000, com base nos argumentos da literatura da Maldição dos Recursos Naturais. Para tal literatura, países especializados em recursos naturais tendem a apresentar baixas taxas de crescimento econômico, sendo esse resultado verificado, sobretudo, em economias com instituiçôes fracas e especializadas em petróleo e minerais. $\mathrm{O}$ artigo também investiga os efeitos da possível maldição quando são controlados alguns dos canais de transmissão expostos pela literatura: volatilidade dos termos de troca, sobrevalorização cambial, investimento, abertura comercial e contexto institucional.

4 Os coeficientes das demais variáveis podem ser solicitados à autora do artigo. 
As evidências obtidas por meio da estimação de modelos ARDL indicam que, no caso brasileiro, a exploraçáo dos recursos naturais (inclusive do petróleo) se mostra benéfica à atividade econômica no longo prazo, especialmente em um cenário de retomada do investimento, de abertura comercial e de melhora do quadro institucional, contrariando os argumentos da Maldição dos Recursos Naturais. No curto prazo, os efeitos das exportações de petróleo são negativos, não se revertendo em estímulos ao PIB, contudo, se tornam insignificantes caso se mantenham sob controle as demais variáveis que afetam o desempenho da economia.

Destarte, as evidências empíricas sinalizam que o petróleo pode ser visto como uma "bênção" para o país, desde que determinadas condiçóes sejam satisfeitas. Assim, adverte-se a necessidade de se consolidarem os fundamentos da economia, com direcionamento de parcela dos recursos obtidos na exploração do petróleo para investimentos em capital físico e em atividades de $\mathrm{P} \& \mathrm{D}$ voltados à diversificação da estrutura produtiva para setores de conteúdo tecnológico sofisticado, a fim de diminuir a dependência de condiçôes favoráveis aos produtos primários. A melhora do quadro institucional, com medidas eficazes de combate à corrupçáo e às atividades rent-seeking em geral, também deve ser priorizada para retomar a confiança dos agentes econômicos, potencializando os efeitos positivos da atividade petrolífera sobre a economia.

Embora as evidências internacionais retratem com recorrência o problema da maldição dos recursos naturais em países especializados em petróleo, destaca-se que o setor é caracterizado por fortes ligaçóes com outros segmentos da economia, podendo gerar externalidades positivas em razão do avanço tecnológico inerente à exploraçáo do recurso. No caso brasileiro, esta pode ser uma boa oportunidade para alavancar os efeitos de transbordamento da atividade, visto que a exploração em águas profundas requer o estímulo à inovação, com potencial para o país se tornar líder em tecnologia offshore e exportador de bens e serviços na área. Todavia, esse processo precisa ser enfrentado internamente, sob risco de o país se tornar ainda mais dependente da tecnologia de fornecedores estrangeiros. Portanto, para o Brasil, a diferença nos efeitos do petróleo sobre o crescimento está em o país apenas expandir a produção e a exportação com o pré-sal, correndo o risco de enfrentar a Maldiçâo dos Recursos Naturais; ou em aproveitar a oportunidade para fomentar a inovação, com a criação de tecnologias e produtos estratégicos que potencializem as externalidades positivas da atividade.

Finalmente, compete ressaltar algumas limitações da análise empírica efetivada no artigo. Uma delas é o uso das exportaçôes de petróleo (e de commodities 
totais) em proporção do PIB como medida de abundância dos recursos naturais. Mensurada desta forma, a variável pode sofrer problemas de endogenia, sendo afetada por políticas macroeconômicas e outras que influenciam o resultado do PIB. Contudo, tal especificação é mantida com respaldo na literatura, dada a dificuldade de se obter uma medida mais adequada para captar o volume daqueles recursos em frequência trimestral.

Outra limitação se associa à participação do petróleo no PIB brasileiro, que ainda se mostra relativamente baixa quando comparada à dos alimentos e minerais. A deflagração da Operação Lava Jato, embora importante por desvendar graves problemas de corrupçáo no país, contribuiu para desacelerar o ritmo da atividade, visto o clima de incerteza que prejudicou os investimentos no setor. No entanto, acredita-se que o petróleo tem potencial para ampliar cada vez mais sua participação no PIB mediante a intensificação da exploração das reservas do pré-sal ao longo do tempo e a recuperação dos investimentos em produção e refino.

Ainda, o período de análise (2000-2017) pode ser considerado curto para se vislumbrarem os efeitos plenos da exploração do petróleo no Brasil, principalmente no que diz respeito às reservas do pré-sal. $\mathrm{O}$ método empírico utilizado tenta corrigir essa distorção ao aplicar defasagens adequadas para refletir a importância de cada variável no modelo, sendo eficiente para captar relaçóes de longo prazo em amostras pequenas de dados. Todavia, o avanço da atividade no futuro (aumento do número de observaçóes) permitirá captar as relações dinâmicas do petróleo sobre o desempenho do PIB e dos canais de transmissão de maneira mais apropriada.

Em termos de pesquisa futura, cabe avaliar a contribuição dos demais tipos de commodities exportadas pelo país, sobretudo alimentos e minerais, visto que estes compóem mais de $50 \%$ da pauta exportadora brasileira.

\section{Agradecimento}

A autora agradece o suporte financeiro do Conselho Nacional de Desenvolvimento Científico e Tecnológico $(\mathrm{CNPq})$ para a realização da pesquisa (Processo 305757/2017-2). 


\section{Referências bibliográficas}

ALEXEEV, M.; CONRAD, R. The elusive curse of oil. The Review of Economics and Statistics, v. 91, n. 3, p. 586-598, August 2009.

AREZKI, R.; VAN DER PLOEG, F. Can the natural resource curse be turned into a Blessing? The Role of Trade Policies and Institutions. International Monetary Fund, March 2007. (IMF Working Paper 07/55).

BADEEB, R.; LEAN, H. H.; CLARK, J. The evolution of the natural resource curse thesis: a critical literature survey. Christchurch, New Zealand: Department of Economics and Finance College of Business and Law University of Canterbury, 2016. (Working Paper n. 5).

BANCO CENTRAL DO BRASIL - BCB. Economia e Finanças. Séries Temporais. Disponível em: https://www.bcb.gov.br/pt-br/\#!/n/SERIESTEMPORAIS. Acesso em: 02 jul. 2018. BRASIL. Ministério da Indústria, Comércio Exterior e Serviços. MDIC. Estatísticas de comércio exterior. Brasília, 2018. Disponível em: http://www.mdic.gov.br/index.php/comercio-exterior/ estatisticas-de-comercio-exterior. Acesso em: 02 jul. 2018.

BRESSER-PEREIRA, L. C. The Dutch disease and its neutralization: a Ricardian approach. Revista de Economia Política, v. 28, n. 1 (109), p. 47-71, jan./mar. 2008.

BROWN, R. L.; DURBIN, J.; EVANS, J. M. Techniques for testing the constancy of regression relationships over time. Journal of the Royal Statistical Society. Series B (Methodological), v. 37, n. 2, p. 149-192, 1975.

BRUNNSCHWEILER, C. N.; BULTE, E. H. The resource curse revisited and revised: a tale of paradoxes and red herrings. Zurich: Center of Economic Research at ETH Zurich, 2006. (Working Paper, n. 06/61).

COLLIER, P.; GODERIS, B. Commodity prices, growth and the natural resources curse: reconciling a conundrum. Oxford: Centre for the Study of African Economies, University of Oxford, August 2007 (Working Paper, n. 276).

CONFEDERAÇÃO NACIONAL DA INDÚSTRIA - CNI. Indicadores CNI. 2018. Disponível em: http://www6.sistemaindustria.org.br/gpc/externo/estatisticaAcessoSistemaExterno. faces. Acesso em: 10 jul. 2018.

CORDEN, W. M.; NEARY, J. P. Booming sector and de-industrialisation in a small open economy. Economic Journal, v. 92, n. 368, p. 825-848, December 1982.

ENGLE, R.; GRANGER, C. W. J. Cointegration and error correction: representation, estimation, and testing. Econometrica, v. 55, n.2, p.251-76, 1987. 
FRANKEL, J. The natural resource curse: a survey. Cambridge, MA: National Bureau of Economic Research, March 2010. (NBER Working Paper 15836).

FURTADO, A. T. Pré-sal, desenvolvimento industrial e inovação. Revista Paranaense de Desenvolvimento, Curitiba, v. 34, n. 125, p.79-100, jul./dez. 2013.

INSTITUTO BRASILEIRO DE GEOGRAFIA E ESTATÍSTICA - IBGE. Sistema IBGE de Recuperação Automática (Sidra). Contas Nacionais Trimestrais. Disponível em: https:// sidra.ibge.gov.br/home/cnt. Acesso em: 02 jul. 2018.

INSTITUTO DE PESQUISA ECONÔMICA APLICADA - IPEA. Indicadores. Disponível em: http://www.ipeadata.gov.br/. Acesso em: 02 jul. 2018.

JOHANSEN, S. Estimation and hypothesis testing of cointegration vectors in Gaussian vector autoregressive models. Econometrica, v. 59, n. 6, p. 1551-1580, 1991.

LAY, J.; MAHMOUD, T. O. Bananas, oil, and development: examining the resource curse and its transmission channels by resource type. Kiel, Germany: Kiel Institute for World Economics, August 2004. (Working Paper n. 1218).

LEDERMAN, D.; MALONEY, W. F. In search of the missing resource curse. Policy Research. Washington, DC: World Bank, November 2008. (Working Paper, 4766).

MEHLUM, H.; MOENE, K.; TORVIK, R. Institutions and the resource curse. The Economic Journal, v. 116, n. 508, p. 1-20, 2006.

MENDES, A. P. A.; TEIXEIRA, C. A. N.; ROCIO, M. A. R. Petróleo e gás. In: PUGA, F.; CASTRO, L. B. de (org.). Visão 2035: Brasil, país desenvolvido. Agendas setoriais para o desenvolvimento. Rio de Janeiro: BNDES, 2018. p. 53-88.

MULWA, R.; MARIARA, J. Natural resource curse in Africa: Dutch disease and institutional explanations. Washington, DC: African Growth and Development Policy, June 2016. (AGRODEP Working Paper, 0029).

MURSHED, S. M. When does natural resource abundance lead to a resource curse? London: International Institute for Environment and Development, March 2004 (Discussion Paper, 04-01).

PAPYRAKIS, E.; GERLAGH, R. The resource curse hypothesis and its transmission channels. Journal of Comparative Economics, v. 32, p. 181-193, 2004.

PESARAN, M. H.; SHIN, Y. An autoregressive distributed-lag modelling approach to cointegration analysis. In: STRØM, S. (ed.). Econometrics and Economic Theory in the 20th Century: The Ragnar Frisch Centennial Symposium. Cambridge: Cambridge University Press, 1999. 
PESARAN, M. H.; SHIN, Y.; SMITH, R. J. Bounds testing approaches to the analysis of level relationships. Journal of Applied Economics. v. 16, n. 3, p. 289-326, 2001.

PESSOA, A. Natural resources and institutions: the "natural resources curse" revisited. Porto: Faculdade de Economia da Universidade do Porto, 2008. (MPRA Paper, n. 8640).

PHILLIPS, P. C. B.; HANSEN, B. E. Statistical inference in instrumental variables regression with I(1) processes. The Review of Economic Studies, v. 57, n. 1, p. 99-125, 1999.

SACHS, J. D.; WARNER, A. M. Natural resource abundance and economic growth. Cambridge, MA: Center for International Development and Harvard Institute for International Development, Harvard University, November 1997.

SACHS, J. D.; WARNER, A. M. Natural resource abundance and economic growth. Cambridge, MA: National Bureau of Economic Research, December 1995 (NBER Working Paper, 5398).

SALA-I-MARTIN, X.; SUBRAMANIAN, A. Addressing the natural resource curse: an illustration from Nigeria. Washington, DC: International Monetary Fund, July 2003. (IMF Working Paper, 03/139).

SATTI, S. L.; FAROOQ, A.; SHAHBAZ, M. Empirical evidence on the resource curse hypothesis in oil abundant economy. Munich: Munich Personal RePEc Archive, 2013. (MPRA Paper, n. 50150).

STIJNS, J. C. Natural resource abundance and economic growth revisited. Berkeley, CA: University of California at Berkeley, 2001. (Working Paper).

TIBA, S.; FRIHKA, M. Africa is rich, Africans are poor! A blessing or curse: an application of cointegration techniques. Journal Knowledge Economics, March 2018.

VAN DER PLOEG, F. Natural resources: curse or blessing? Journal of Economic Literature, v. 42, n. 2, p. 366-420, 2011.

WORLD BANK. Global economics monitor. 2018. Disponível em: https://data.world/worldbank/global-economic-monitor. Acesso em: 02 jul. 2018.

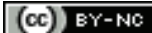

Esta obra foi licenciada sob uma Licença Creative Commons Atribuição-NãoComercial 3.0 Brasil. 
